\title{
ESPAÇO, LUGAR E LITERATURA - O OLHAR GEOGRÁFICO MACHADIANO SOBRE A CIDADE DO RIO DE JANEIRO
}

- FREDERICO ROZA BARCELLOS

\section{RESUMO}

OS ESTUdOS GEOGRÁFICOS REALIZAdOS A PARTIR DA ANÁLISE DE TEXTOS LITERÁRIOS JÁ CONSTITUEM UMA LINHA DE PESQUISA CONSOLIDADA NA GEOGRAFIA INTERNACIONAL. NO ENTANTO, TAL TEMA É POUCO PRIVILEGIADO NA GEOGRAFIA BRASILEIRA, A DESPEITO DA RIQUEZA ESPACIAL QUE APRESENTA A PRODUÇ̃̃O LITERÁRIA. NA RELAC̦ÃO ENTRE GEOGRAFIA E LITERATURA, OS TEXTOS LITERÁRIOS APRESENTAM-SE COMO UM RICO MATERIAL A SER APRECIADO POR NÓS GEÓgRAFOS, pOIS ELES EVOCAM a ALMA dOS LUGARES E 0 COTIDIANO DAS PESSOAS. É NESSE SENTIDO QUE NOSSA PESQUISA CONSISTE EM ANALISAR E INTERPRETAR A REPRESENTAÇÃO dO ESPAÇO GEOGRÁFICO DA CIDADE DO RIO DE JANEIRO DO FINAL DO SÉCULO XIX E INÍCIO DO SÉCULO XX NO DISCURSO ROMANESCO MACHADIANO. DESSA MANEIRA,

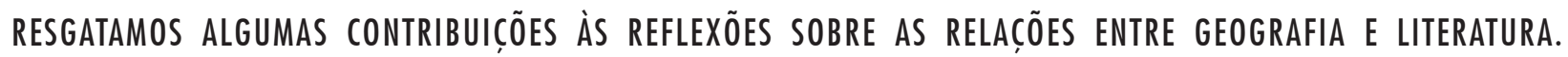
ARgUMENTAMOS QUE OS TEXTOS DE MACHADO DE ASSIS POSSUEM UM AMPLO MOVIMENTO DE TRANSFORMAC̦̃ES NO ESPAÇO URBANO CARIOCA, DEIXANDO PARA TRÁS SUA PAISAGEM COLONIAL. A CIDADE DE FEIÇ̃̃ES COLONIAIS TORNAVASE AGITADA E MODERNA E VIA SEUS ESPAÇOS PÚblicos SEREM TOMAdOS PELA MULTIDÃO, POR NOVOS RITMOS E

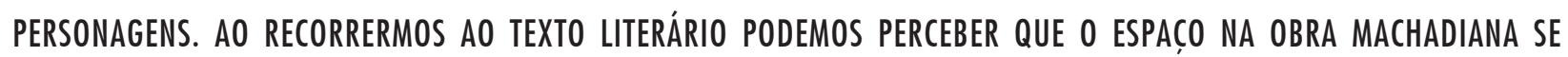
APRESENTA MÚLTIPLO, ORA COMO ESPAÇO, ORA COMO LUGAR, POIS O ESCRITOR SE FIXAVA PRINCIPALMENTE NUM TRECHO

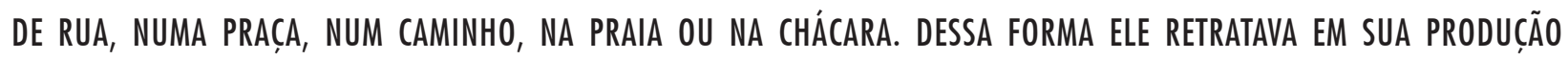
LITERÁRIA FRAGMENTOS DE UMA CIDADE EM TRANSFORMAC̦ÃO. AS RUAS, PRAÇAS E MORROS APARECEM COMO ESPAÇOS DOTADOS DE VALOR E SENTIMENTOS, ONDE SÃO ARTICULADAS VIVÊNCIAS E EXPERIÊNCIAS CARACTERIZANDO-OS COMO LUGAR, ENQUANTO A ÁREA LITORÂNEA PODE SER CARACTERIZADA COMO SENDO UM ESPAÇO $O$ QUE PASSOU POR UMA VALORIZAÇÃO SIMBÓLICA E ECONÔMICA, PRINCIPALMENTE, ATRAVÉS DO DISCURSO MÉdICO.

PalaVRas-ChaVE: ESPAÇO, LUGAR, CULTURA, LITERATURA, RIO DE JANEIRO.

INTRODUÇÃO

A abordagem cultural possui uma longa tradição na pesquisa geográfica, no que tange aos estudos sobre a dimensão cultural do espaço. Nesse sentido, o Brasil apresenta-se como um rico labo- ratório para que várias temáticas sejam exploradas pela ciência geográfica, evidenciando o quanto esta pode contribuir para o desenvolvimento de estudos que abarcam a cultura e suas mais variadas formas de manifestação no espaço. A diversidade 
cultural do Brasil é enorme, portanto os geógrafos que se interessam pela abordagem cultural têm diante de si um imenso terreno para pesquisar, como aponta Claval (1999a). Como exemplo da gama de assuntos que podem ser analisados pela Geografia através da perspectiva cultural, observamos que os testemunhos literários são cada vez mais abordados sistematicamente, assim como os testemunhos fornecidos por gravuras ou pinturas antigas, fotografias, filmes e religião.

A Geografia, que hoje procura novas alternativas para formas de apreensão do espaço, muito tem a ganhar através da incorporação crítica de discursos como o da literatura, os quais podem servir como recurso de renovação metodológica para o ensino desta disciplina. Nesse sentido, Dimas (1994) aponta que o espaço pode apresentar-se como componente principal da narrativa, sendo fundamental, quando não determinante, no desenvolvimento da ação. No entanto, a geografia brasileira tem se privado de participar deste debate, a despeito da riqueza espacial que apresenta sua produção literária (DIMAS, 1994).

A literatura ocupa um importante lugar na investigação geográfica desde o início dos anos 70, coincidindo com o período de renovação nos estudos geográficos focalizando a dimensão cultural. Segundo Brosseau (1996), o estruturalismo permitiu que a literatura alcançasse um privilegiado estatuto como domínio de reflexão, favorecendo o contato entre diversas disciplinas que se desenvolviam até então de forma mais ou menos independente, possibilitando assim numerosas trocas interdisciplinares. O estruturalismo permitiu dessa forma a multiplicação das reflexões sobre o discurso, sobre o texto e sobre diversos sistemas significantes. $\mathrm{O}$ interesse pela temática geografia e literatura permitiu que várias tendências se tornassem matéria de reflexão, tanto em relação à crítica social, quanto em relação ao que está em jogo no discurso da representação do espaço e dos lugares. Dentro deste contexto, a literatura moderna deixou de ter como tema central, entre os geógrafos, o meio ambiente e passou a dar uma maior relevância ao lugar e seus significados e à relação entre as pessoas e o lugar, como nos aponta Pocock (1981). Dessa forma, a literatura não somente reconstitui uma experiência, como também formula experiências.

Nesse sentido, o presente texto tem por objetivo analisar e interpretar a representação do espaço geográfico da cidade do Rio de Janeiro do final do século XIX e inicio do século XX no discurso romanesco machadiano, levando-se em consideração os romances Memórias Póstumas de Brás Cubas, Dom Casmurro e Quincas Borba. Antes, porém, consideramos necessária uma breve exposição de algumas contribuições teóricas sobre a temática espaço e literatura, assim como a discussão sobre os conceitos de espaço e lugar.

\section{O Lugar da Literatura na Geografia Cultural -} UMA DISCUSSÃO TEÓRICA

$\mathrm{Na}$ Geografia, a abertura às pesquisas tendo como referencial a literatura ocorreu sobretudo na Geografia anglo-saxônica de inspiração humanista. O desenvolvimento dos trabalhos em questão, longe de representar uma reflexão sobre os sistemas de produção, sobre as estruturas semióticas ou simbólicas, sobre a crítica ideológica, participa de uma visão fenomenológica destinada a remeter o sujeito, os sentidos, os valores aos estu- 
dos em Geografia. Conforme nos aponta Brosseau (1996), a partir da década de 1970, a Geografia Humanista e a Geografia Crítica emergem como reação à produção da Nova Geografia, sugerindo que o objeto de estudo geográfico deveria dar uma importância maior ao lugar e à relação que os indivíduos estabelecem com ele. Em relação à literatura, esta teria importância para o estudo geográfico por transcrever as experiências concretas que o autor tem com os lugares, sendo vista assim como resultado de percepção da qual guardará o vestígio. O romance é visto como o encontro entre o mundo objetivo e a subjetividade humana, isto quer dizer que o romance daria conta não apenas dos aspectos objetivos da realidade, mas também de sua subjetividade. No entanto, Brosseau contesta a perspectiva da fenomenologia, a qual trabalha com a idéia de que o corpo e a linguagem seriam co - fundadores da experiência. Segundo o autor, a linguagem com a qual um indivíduo representa uma experiência no exato momento em que ele a viveu através de seu corpo e sua linguagem é diferente da linguagem mobilizada pelo romance, mesmo quando este reconstitui uma experiência igual. Neste sentido, observa-se uma tendência a tomar o romance, em especial o realista, de forma utilitária em relação às experiências pessoais do autor com um dado lugar. Tais experiências são tidas como verdadeiras e desta forma a análise literária retém-se no plano do imaginário e negligencia o processo criativo do autor e do uso que este faz dos recursos da linguagem. Para o referido autor, tal abordagem é considerada problemática e empobrecedora para os estudos geográficos.

Ainda durante a década 1970 surge uma outra proposta de análise literária em Geografia, oriun- da da corrente denominada Geografia Crítica. Segundo esta linha de pesquisa, a literatura teria como um dos seus objetivos mostrar a realidade como esta deveria ser, apresentando uma função libertadora que seria contrária ao monopólio da realidade estabelecida. A interpretação literária, segundo esta perspectiva, acredita na importância de se relocar o texto ao contexto social e histórico de sua produção. A literatura deve estar a serviço da mudança e se opor à ideologia dominante. Porém, Brosseau nos chama a atenção para o perigo de transformar a literatura em movimento militante e de condenar aquela não engajada como sendo uma má literatura.

Sobre as correntes de análise literária em Geografia - literatura como transcrição da experiência dos lugares e literatura como crítica da realidade ou da ideologia dominante - Marc Brosseau tece uma crítica interessante para o nosso debate. Todas as visões acima apresentadas tomam a literatura de uma maneira instrumental, através da qual sua importância não estaria em sua estrutura, mas nas relações que esta faz com a realidade, tendo, portanto, uma importância alheia a si. Segundo o autor, esta "característica instrumental repousa sobre motivos diferentes: para uns a literatura serve de fonte de informações, para outros para relocar o homem no centro das preocupações, ou ainda para criticar o status quo por uma melhor justiça

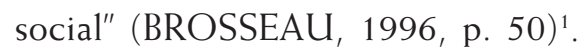

Outra importante contribuição de Marc Brosseau aos estudos geográficos sobre textos literários diz respeito à proposição do método dialógico. O diálogo aparece como uma opção plausível para a análise do romance, sendo uma possibilidade de comunicação entre Geografia e Literatura 
enquanto campos autônomos do conhecimento.

Diferentemente de uma interpretação do texto em sua totalidade, a proposta de Brosseau (1996) é de uma compreensão dos espaços e dos lugares no texto, de forma não estandartizada, a partir do método do dialogo.

De acordo com esta perspectiva, para que o diálogo seja estabelecido, o romance não deve ser tratado como um objeto, mas como um outro sujeito, visto que um diálogo só pode ocorrer entre dois sujeitos. O romance, segundo Brosseau (1996), apresenta uma forma específica: ele não é um discurso científico, logo não diz a mesma coisa e nem apresenta a mesma forma que aquele. Por isso, ele não pode ser tratado como uma ferramenta, mas deve ser respeitado em sua especificidade.

Assim, Brosseau argumenta que o método dialógico procura evitar

a crença na capacidade da ciência exprimir em suas palavras aquilo que o romance diz (escreve). O diálogo é somente uma outra estratégia que permite ao geógrafo entrar em contato com o romance, interrogar sua própria relação com a linguagem e a escrita graças a um encontro com este outro sem buscar assimila-lo. Colocar o romance como sujeito, como totalidade, não significa nada além de dizer que ele nos é impermeável, embora baja uma maneira própria (e esta pode ser verdadeira para cada romance particular) de produzir sentido, uma coerência de sentidos, que resiste aos mais sutis esforços do analista em o transformar em objeto (BROSSEAU, 1996, p. 60-61)2.

Um outro ponto destacado por Brosseau é o da importância que a descrição apresenta para o estudo do espaço romanesco. No entanto, é preciso ressaltar que, ao contrário do caráter meramente descritivo de uma Geografia Regional Clássica, a descrição estaria intimamente ligada à explicação. Segundo Brosseau (1996), a descrição pode tornar-se o lugar onde a narrativa é relança$\mathrm{da}$, recontando os eventos sobre os quais esta passaria em silêncio.

Por fim, a abordagem da história literária e dos gêneros traz a contribuição de Bakthin com o conceito de cronótopo, que busca alcançar a "a correlação essencial das relações espaço - temporais" ${ }^{\prime \prime 3}$ (BAKTHIN citado por BROSSEAU). Esta noção para Marc Brosseau (1996, p. 100) "é uma ferramenta preciosa na tentativa de apreender os problemas do espaço - tempo no conjunto do romance e nos ensina que não é possível compreender um sem o outro ${ }^{\prime \prime}$. Dessa forma, o recurso ao conceito de cronótopo seve para que se defina mais precisamente o tipo de universo com o qual o diálogo será estabelecido, quando do contato com o romance.

Em uma outra corrente de análise literária em Geografia, a literatura é vista como uma forma de se representar o real, sentido, no qual os processos de estruturação do simbólico estão presentes. Tanto Brosseau (1996) quanto Kneale (2003) compartilham dessa idéia, pois para ambos não há condições de se estabelecer uma correspondência exata entre a paisagem real e o romance, pois o romance é uma representação do real. A representação, na concepção de Henriques (1996, p. 51), é

uma verdade parcial porque sendo produzida necessariamente por um autor se encontra sempre afetada pelas prioridades que definem o seu 
ponto de vista e pelo quadro contextual em que esse mesmo autor está inserido, isto significa dizer que as representações partem não só do campo de referência extratextual, ou seja, dos dados do mundo real, mas também de um campo de referência intertextual que no fundo diz respeito ao contexto produzido por outros textos.

O romance na verdade funciona como testemunho de pessoas reais que ele põe em cena por meio de ficção. Seguindo nesta mesma linha de raciocínio, Bastos (1998) afirma que a representação do real se dá através de uma relação entre produção e literatura, na qual há um processo dialético entre texto e a leitura, sendo difícil para o leitor elaborar significações próximas às imaginadas pelo escritor. É nesse momento que surgem algumas dificuldades de se realizar uma análise geográfica através de um texto literário, seja ele um poema, seja ele um romance, pois este representa ao mesmo tempo,

um espaço privilegiado de expressão da temática dos conflitos sociais e ideológicos de uma dada cultura, por reunir toda uma gama de contradições "inventadas" pelo narrador a partir dos conflitos existentes no seu borizonte de experiências, vivencias e expectativas sociais. Bastos (1998, p. 57)

A mesma preocupação relacionada à representação do real, é observada em Short (1991), para quem os textos são produzidos com base na particularidade e na imaginação individual dos autores cuja criatividade é condensada em preocupações sociais, com concessões a argumentos específicos e formas pessoais aos textos, os quais são subseqüentemente interpretados de acordo com o alcance da criatividade dos leitores. Os textos literários, portanto, não podem ser reduzidos a uma mera incorporação de mitos e articulações de ideologias, eles soam muito mais que isso, pois nos comunicamos através deles e entendê-los é entender as mensagens passadas entre os diferentes membros da sociedade.

Ao se analisar os textos literários, é preciso ter um certo cuidado, pois, segundo Short (1991), os mesmos contêm uma dialética do contexto social, expressa tanto no romance, quanto na poesia ou no cinema, além de também apresentar um impulso criativo individual do escritor. Isto quer dizer que a interpretação dos textos literários deve ser realizada levando-se em consideração uma visão socioeconômica que não seja pré-definida sobre um texto e que o mesmo não seja destituído de amplo significado social. Assim o texto literário não se torna um produto neutro, já que tanto escritor quanto leitor consumiram o mesmo texto de diversas formas possíveis, segundo suas próprias significações e valores.

Sobre as significações e valores, Haesbaert (1997, p. 30), ressalta de forma expressiva a tentativa de superar a separação entre sensibilidade e razão, poesia e ciência, argumentando que seja através de um poema ou de um romance,

cada cultura, cada grupo e às vezes até mesmo cada individuo preenche o seu espaço não apenas com um conjunto de instrumentos e utilitários, mas também de emoção e sensibilidade, pois amamos, sofremos e podemos, pelo menos na imaginação expressar todos os sentimentos e todos os espaços do mundo. 
As múltiplas significações são próprias do discurso simbólico que caracteriza o poema. A escolha de um símbolo não pode privar-se de toda referência ao real, podemos associar essas reflexões à Geografia e lembrar que muitos espaços expressam muito mais do que a manifestação concreta de seus prédios, estradas e montanhas. Neles há espaços a partir dos quais se cria uma leitura simbólica, que pode ser sagrada, poética ou simplesmente folclórica, capaz de fortalecer uma identidade coletiva e também territorial, conforme aponta Haesbaert (1997). Podemos nos arriscar a dizer que o romance realista, mas especificamente a obra machadiana, oferece pistas referentes ao espaço, permitindo-nos acompanhar a trajetória romanesca e dos personagens de forma a não prestar atenção exclusiva à ação. É importante ressaltar que na apreensão do espaço geográfico, conforme argumentado por Bastos (1998), existe uma dimensão concreta - produção do espaço material - e uma dimensão simbólica - as representações - que se interagem. O espaço é representado segundo um imaginário social em que não se deve negar a materialidade.

Segundo Cosgrove (2000, p. 38), "é a imaginação que metamorfoseia a comunidade humana e o ambiente natural em uma significativa unidade de espaço". O mesmo autor nos relata que a geografia cultural lida, por definição, com grupos humanos, suas interrelações e ações coletivas, transformando a natureza e fazendo da comunicação o alicerce da intersubjetividade, ou seja, dos valores e crenças compartilhados que se constituem na imaginação coletiva e definem a cultura não-material. Neste caso a literatura se enquadra perfeitamente. A imaginação poética é a que desperta maior interesse nos geógrafos culturais, no sentido em que gera novos sentidos, sendo a criatividade poética o elemento que produz culturas e as diferencia. Portanto, os geógrafos culturais interessados na questão do significado do mundo têm se dedicado cada vez mais ao papel simbólico da linguagem em nossas relações com o mundo natural.

A apreensão do espaço geográfico pela via do discurso literário do romance busca uma imbricação entre o real e o imaginário, entre o objetivo e o subjetivo, a qual nos fornece um entendimento do discurso literário como forma de representação do espaço real. Nesse sentido Cosgrove (2000, p. 50) afirma sobre o imaginário que

tanto o passado, quanto o futuro são espaços da imaginação, já que nenbum deles existe como um dado proveniente dos sentidos. O passado possui como dimensão simbólica uma ideologia da imaginação, enquanto que o futuro tem como dimensão simbólica a utopia, portanto ideologia e utopia são elementos necessários e complementares do imaginário social em qualduer cultura. A ideologia oferece mitos e símbolos fundamentais, que alicerçam as instituições e as ações coletivas através do ritual, enquanto que a utopia faz parte da imaginação social dirigida ao futuro que desafia a tradição e busca a ruptura com o presente.

Dentre as importantes contribuições realizadas por pesquisadores brasileiros para a análise do conteúdo geográfico em criações romanescas podemos destacar o livro O mapa e a Trama (2002) do professor Carlos Augusto Monteiro, porém admitindo algumas ressalvas. Nesse trabalho o autor tem grande preocupação em descrever as paisagens 
existentes nos vários romances que ele utilizou em seus estudos, não havendo maior preocupação na fundamentação teórica acerca da relação entre a Geografia e a Literatura. Na verdade Monteiro não realiza uma interpretação mais aprofundada dos romances que foram utilizados como material de análise. Esta característica está muito presente na leitura que ele faz da obra de Guimarães Rosa, Corpo de Baile. No melhor estilo lablacheano, ele descreve com minúcias o sertão presente na obra de Guimarães Rosa, sem nenhuma preocupação interpretativa do romance.

Em uma outra perspectiva de análise dos textos literários, Moretti (2003) em seu Atlas do Romance Europeu 1800 - 1900 analisa o romance e suas relações internas, tornando visível a ligação entre Geografia e Literatura. Segundo o autor, a geografia literária pode se referir a duas coisas muito diferentes: o espaço na literatura que é ficcional e a literatura no espaço que é o espaço histórico real. A distinção entre os dois espaços não afeta o método de pesquisa, que é o mesmo em toda parte e se baseia no uso sistemático de mapas. De mapas não como metáforas, mas como ferramentas analíticas que dissecam o texto de uma forma incomum, trazendo à luz relações que de outro modo ficariam ocultas. Os mapas literários nos permitem ver a natureza espacial das formas literárias (suas fronteiras e rotas favoritas) e também trazem à luz a lógica interna da narrativa, ou seja, o domínio semiótico em torno do qual um enredo se aglutina e se organiza.

A Geografia, segundo o autor, não é um recipiente inerte, não é uma caixa onde a história cultural ocorre, mas uma força ativa que impregna o campo literário e o conforma em profundidade. A relação entre Geografia e literatura pode se tornar explicita, pois podemos mapeá-la, ou seja, é uma ligação que se torna visível. Ao analisar os romances, Moretti enfatiza a relação dos mesmos com o tempo, não deixando de sugerir que o componente espacial é tão notável quanto o temporal.

\section{ESPAÇO E LUGAR}

A contribuição de Milton Santos através de sua vasta obra para a discussão do conceito de espaço é enorme. Em A Natureza do Espaço ele discute o espaço como sendo "um conjunto indissociável de sistemas de objetos e sistemas de ações, não considerados isoladamente, mas como o quadro único no qual a história se dá". Segundo Santos (2002, p. 63), no começo

a natureza era selvagem, formada por objetos naturais, que ao longo da bistória vão sendo substituídos por objetos fabricados, fazendo com que a natureza artificial tenda a funcionar como uma máquina. Através da presença desses objetos técnicos - estradas de rodagem, fábricas, fazendas, portos, cidades, o espaço é marcado por esses acréscimos, e the dão um conteúdo extremamente técnico.

Para Santos (2002, p. 104) adicionalmente,

é um sistema de valores que se transforma permanentemente. O espaço uno e múltiplo, por suas diversas parcelas, e através do seu uso, é um conjunto de mercadorias, cujo valor individual é função do valor que a sociedade, em um dado momento, atribui a cada pedaço de matéria, isto quer dizer que o espaço é a sociedade. 
É esta sociedade que anima as formas espaciais, atribuindo-lhes um conteúdo, uma vida. Uma casa vazia ou um terreno baldio, um lago, uma montanha são transformados em espaços a partir do momento em que lhes são atribuídos determinados valores. O espaço é a síntese, sempre provisória, entre o conteúdo social e as formas espaciais.

$\mathrm{Na}$ geografia humanista o lugar passa a ser o conceito - chave mais relevante. A contribuição de Tuan sobre a discussão dos conceitos de espaço e lugar, levando-se em consideração a perspectiva da experiência é inegável. Em sua opinião, espaço e lugar

são termos familiares que indicam experiências em comum. O espaço é mais abstrato do que o lugar. O que começa como espaço indiferenciado transforma-se em lugar à medida que o conbecemos melhor e o dotamos de valor. As idéias de espaço e lugar não podem ser definidas uma sem a outra. A partir da segurança e estabilidade do lugar estamos cientes da amplidão, da liberdade e da ameaça do espaço, e vice-versa. Além disso, se pensamos no espaço como algo que permite movimento, então lugar épausa, cada pausa no movimento torna possível que localização se transforme em lugar. (TUAN, 1983, p. 6)

O lugar, para Tuan (1983, p. 14), "é uma concreção de valor, embora não seja uma coisa valiosa, que possa ser facilmente manipulada ou levada de um lado para o outro; é um objeto no qual se pode morar, isto quer dizer que o lugar é um mundo de significado organizado". Nesse sentido, Ferreira (2000) aponta que o lugar seria um centro de significações insubstituível para a fundação de nossa identidade como indivíduos e como membros de uma comunidade, associando-se, desta forma, ao conceito de lar. Esse é essencialmente um conceito estático, pois se víssemos o mundo como processo, em constante mudança, não seríamos capazes de desenvolver nenhum sentido de lugar.

Tuan (1983, p. 40) acrescenta que "os lugares, assim como os objetos, são núcleos de valor, e só podem ser totalmente apreendidos através de uma experiência total englobando relações íntimas, próprias do residente, e relações externas próprias do turista". O lugar torna-se realidade a partir da nossa familiaridade com o espaço, não necessitando ser definido através de uma imagem precisa, limitada. Quando o espaço nos é inteiramente familiar, torna-se lugar.

\section{O Lugar e o Espaço na Obra Machadiana}

Após apresentarmos, em linhas gerais, algumas contribuições teóricas sobre a temática espaço e literatura, esta seção é reservada à análise geográfica dos textos literários de Machado de Assis. Neste percurso analítico, daremos ênfase aos conceitos de espaço e lugar para realizar a interpretação dos romances machadianos.

A presença de ruas e praças do centro velho da cidade do Rio de Janeiro, assim como dos morros, nos romances de Machado de Assis, é elucidativa de como esses espaços, a partir do momento que articulam vivências e experiências, ao mesmo tempo em que passam a ser dotados de valor e sentimentos, tornam-se lugares na narrativa machadiana. Espaço urbano esse que sofreu inúmeras intervenções a cada uma das fases de crescimento da cidade e que teve como resultado a criação de ruas e praças que hoje fazem parte da paisagem da ci- 
dade do Rio de Janeiro. A seguir são apresentados alguns fragmentos que mostram como o lugar está presente na obra machadiana.

No trecho seguinte, de Memórias Póstumas de Brás Cubas, é nítido o sentimento e a vivência que o escritor cria em relação ao seu espaço de infância, identificando dessa forma a representação do lugar.

Nunca em minba infância, nunca em toda minha vida, achei um menino mais gracioso, inventivo e travesso. Era a flor, e não já da escola, senão de toda cidade. A mãe, viúva com alguma coisa de seu, adorava o filbo e trazia-o amimado, asseado, enfeitado, com um vistoso pajem atrás, um pajem que nos deixava gazear a escola, ir caçar ninbos de pássaros, ou perseguir lagartixas nos morros do Livramento e da Conceição, ou simplesmente arruar, à toa, como dois peraltas sem emprego (p.46).

A volta de Brás Cubas de Portugal é um outro indício do escritor da representação do espaço como lugar na obra machadiana.

Vim. Não nego que, ao avistar a cidade natal, tive uma sensação nova. Não era efeito da minha pátria política; era-o do lugar da infância, a rua, a torre, o chafariz da esquina, a mulber de mantilba, o preto do ganbo, as coisas e cenas da meninice, buriladas na memória (p.66).

Há um trecho do romance Dom Casmurro que mostra o personagem principal relembrando de momentos ocorridos antes da sua entrada para o seminário. E são lembranças importantes, pois dizem respeito a momentos em que ele viveu com
Capitu na rua onde moravam. São memórias em que o lugar é representado no romance.

E se a comparação não vale, porque as chinelas são ainda uma parte da pessoa e tiveram o contato dos pés, aqui estão outras lembranças, como a pedra da rua, a porta da casa, um assobio particular, um pregão de quitanda, como aquele das cocadas (...). (...) Justamente quando contei o pregão das cocadas, fiquei tão curtido de saudades que me lembrou fazê-lo escrever por um amigo, mestre de música, e grudá-lo às pernas do capítulo (p.83).

É importante ressaltar que lendo os textos machadianos fica clara, a presença de um espaço dotado de valor e sentimento, caracterizando-o como sendo um lugar, segundo o conceito discutido por Tuan (1983). As ruas, praças e morros são espaços que se transformam em lugares, os quais estão representados nos romances machadianos.

A representação da área litorânea nos romances de Machado de Assis é uma característica marcante da presença do espaço nos textos machadianos. Tanto isso é verdadeiro que um dos personagens do romance Dom Casmurro morre no mar. No entanto, é importante ressaltar que as áreas litorâneas nem sempre tiveram um papel de destaque e prestígio perante a sociedade carioca como um lugar aprazível e de prática do lazer.

O discurso que valoriza as áreas litorâneas praia e mar - como locais de saúde e lazer é constituído no âmbito da comunidade médica ao longo do século XIX. A valorização das praias através do discurso médico não apenas serviu para modificar o seu modo de apreciação, mas também foi 
importante, segundo Ferreira e Silva (2000), na valorização econômica dos espaços litorâneos e na criação de um vetor de ocupação das elites em direção a estes setores da cidade. $\mathrm{O}$ que na verdade observamos, é uma valorização simbólica e material destes lugares que antes eram desprezados.

Depois do que foi exposto acima podemos nos arriscar a dizer que a praia é representada nos textos machadianos como sendo um espaço e não um lugar, pois segundo Santos (2002, p. 104) "o espaço é um sistema de valores que se transforma permanentemente". E com as áreas litorâneas da cidade do Rio de Janeiro não foi diferente. Elas passaram a representar uma nova área de ocupação residencial para os grupos mais abastados da sociedade carioca. Eis alguns trechos que elucidam o que foi dito anteriormente.

A nossa vida era mais ou menos plácida. Quando não estávamos com a família ou com os amigos, ou se não íamos a algum espetáculo ou serão particular, passávamos as noites à nossa janela da Glória, mirando o mar e o céu, a sombra das montanbas e dos navios, ou a gente que passava na praia. Às vezes, eu contava a Capitu a bistória da cidade, outras dava-lhe notícias de astronomia (p.132).

Nós não podíamos ter os corações agora mais perto. As nossas mulheres viviam na casa uma da outra, nós passávamos as noites cá ou lá conversando, jogando ou mirando o mar, os dois pequenos passavam dias, ora no Flamengo, ora na Glória (p.147).

Quanto às puras economias de dinheiro, direi um caso, e basta. Foi justamente por ocasião de uma lição de astronomia, à praia da Glória.
Sabes que alguma vez fiz cocbilar um ponco. Uma noite perdeu-se em fitar o mar, com tal força e concentração, que me deu ciúmes (p.133). Escobar cumpriu o que disse, jantava conosco, e ia-se à noite. Sobre tarde descíamos à praia ou íamos ao Passeio Público, fazendo ele os seus cálculos, eu os meus sonbos. Eu via o meu filbo médico, advogado, negociante, meti-o em várias universidades e bancos, e até aceitei a bipótese de ser poeta (p.137).

É bem nítido, nos textos de Machado de Assis a presença da praia como um local de residência de grupos mais abastados da sociedade carioca. A ocupação das áreas litorâneas na cidade do Rio de Janeiro é representada nos romances machadianos como sendo um espaço em transformação, principalmente depois da valorização econômica e simbólica que essas áreas sofreram através do discurso médico, caracterizando dessa forma o espaço como sendo uma síntese, mesmo que provisória, entre o conteúdo social e as formas espaciais (SANTOS, 2002).

\section{CONSIDERAÇÕES FinAIS}

Certamente este não é o primeiro e nem o último estudo sobre a interpretação dos textos machadianos. Porém acreditamos contribuir com o debate na Geografia Cultural brasileira sobre as várias possibilidades de se realizarem estudos geográficos que considerem a Literatura como importante forma de representação espacial.

Podemos constatar que a representação espacial nos textos machadianos se apresenta de diferentes formas. As ruas, praças e morros aparecem nos romances como espaços dotados de valor e 
sentimentos, onde são articuladas vivências e experiências, caracterizando-os como lugar, enquanto a área litorânea pode ser caracterizada como sendo um espaço, o qual passou por uma valorização, principalmente, através do discurso médico. A partir daí não houve somente um novo modo de apreciação da praia, mas também uma valorização econômica dos espaços litorâneos com a criação de um vetor de ocupação das elites em direção a estes setores da cidade. Essa valorização das áreas litorâneas trouxe a "reboque" toda uma repercussão no processo de produção do espaço, pois as tornaram do ponto de vista residencial em espaços mais valorizados no final do século XIX e início do século XX.

É importante ressaltar que Machado de Assis, assim como qualquer outro escritor, não tem a preocupação em retratar fielmente aspectos da realidade. Porém quando lemos os textos machadianos temos a nítida impressão que o escritor não deixa de representar características importantes do espaço urbano de sua cidade natal. Surge dessa forma o Passeio Público, o morro do Livramento, as ruas do centro da cidade, com destaque para a rua do Ouvidor, a área litorânea, sendo as praias da Glória e do Flamengo e a enseada de Botafogo as mais representadas nos textos machadianos.

A Geografia não aborda apenas a paisagem. Há outras abordagens, por exemplo, aquela que enfatiza o espaço e os lugares. Na perspectiva machadiana as praças, ruas, morros assumem, em alguns casos as características de lugares, que mantêm relações com a trama, não se constituindo em meros palcos.

Finalizamos o presente texto enfatizando que os textos literários não só podem como devem ser utilizados como um rico material a ser interpretado sobre as várias representações do espaço e que a pesquisa em tela constitui-se uma dentre as inúmeras possibilidades de análise geográfica da obra de Machado de Assis.

\section{NOTAS}

${ }^{1}$ Tradução do autor.

${ }^{2}$ Tradução do autor.

${ }^{3}$ Tradução do autor.

${ }^{4}$ Tradução do autor.

\section{REFERÊNCIAS BIBLIOGRÁFICAS}

ASSIS, Joaquim M. Machado de. Quincas Borba. São Paulo: Editora Martins Claret, 2004.

ASSIS, Joaquim M. Machado de. Memórias Póstumas de Brás Cubas. São Paulo: Abril Cultural, 1992.

ASSIS, Joaquim M. Machado de. Dom Casmurro. São Paulo: Abril Cultural, 1981.

BASTOS, A R. V. R. Espaço e Literatura: Algumas Reflexões Teóricas. Espaço e Cultura, UERJ, Rio de Janeiro, n 5, p. $55-$ 66, 1998.

BROSSEAU, M. Des Romains - géographes - Essai. Paris: L'Harmattan, 1996

CLAVAL, P. Reflexões sobre a Geografia Cultural no Brasil. Espaço e Cultura, UERJ, Rio de Janeiro, nº 8, pp. 7 - 29, 1999.

COSGROVE, D. Mundo de Significados: Geografia Cultural e Imaginação. In: CORREAA, R. L \& ROSENDAHL, Z. (orgs). Geografia Cultural: Um Século (2). Rio de Janeiro: EdUERJ, 2000.

DIMAS, A. Espaço e Romance. São Paulo: Editora Ática, 1994.

FERREIRA, L. F. Acepções Recentes do Conceito de Lugar e sua Importância para o Mundo Contemporâneo. Revista Território, Rio de Janeiro, ano V, nº 9, Jul/Dez de 2000.

FERREIRA e SILVA, M. G. A Praia e o Imaginário Social: Discurso Medico e Mudança de Significados na Cidade do Rio de Janeiro. In: ROSENDAHL, Z. \& CORREAA, R. L. (orgs). Paisagens. Imaginário e Espaço. Rio de Janeiro: EdUERJ, 2001.

HAESBAERT, R. Território, Poesia e Identidade. Espaço e Cultura, UERJ, Rio de Janeiro, nº 3, p. 20 - 32, 1997.

HENRIQUES, E. B. A Problemática da Representação no Pensamento Geográfico Contemporâneo. Culturas, Identidade e Território, Inforgeo/Associação Portuguesa de Geógrafos, nº 11,1996

KNEALE, J. Secondary Wordls - readings novels as geographical research. In: Cultural Geograpby in Practice. London: Arnold, 2003.

MONTEIRO, C. A de F. O mapa e a trama: Ensaios sobre o conteúdo geográfico em criações romanescas. Florianópolis: Editora da UFSC, 2002.

MORETTI, F. Atlas do Romance Europeu 1800 - 1900. São Paulo: Boitempo Editoral, 2003. 
POCOCK, D. C. D. Geography ad Literature. Progress in Human Geograpby, n 12(1), pp. 87 - 102, 1988.

POCOCK, D. C. D. Humanistic Geogarpby and Literature: Essays in the Experience of Place. Londres: Croon Holm, 1981.
SANTOS, M. A Natureza do Espaço. São Paulo: Edusp, 2002. SHORT, J. Imagined Countries: Society, Culture and Environment. New York: Routledge, 1991.

TUAN, Y. F. Espaço e Lugar. São Paulo: DIFEL, 1983.

\section{ABSTRACT}

THE GEOGRAPHIC STUDIES MADE FROM THE ANALYSIS OF LITERARY TEXTS ALREADY ESTABLISH AN INVESTIGATION LINE CONSOLIDATED IN INTERNATIONAL GEOGRAPHY. HOWEVER, THIS THEME IS LITTLE PRIVILEGED IN BRAZILIAN GEOGRAPHY, DESPITE THE AMAZING RICHNESS THAT THE LITERARY PRODUCTION PRESENTS. IN THE RELATIONSHIP BETWEEN GEOGRAPHY AND LITERARY, THE LITERARY TEXTS SHOW THEMSELVES AS A RICH MATERIAL TO BE APPRECIATED BY US GEOGRAPHERS, AS THEY EVOKE THE PLACES, SOUL AND PEOPLE DAILY LIVES. IN THIS DIRECTION, OUR RESEARCH CONSISTS IN THE ANALYSIS AND INTERPRETATION OF RIO DE JANEIRO CITY GEOGRAPHIC SPACE REPRESENTATION AT THE END OF THE 19 CENTURY AND THE BEgINNING OF 20믄 CENTURY IN THE ROMANTIC MACHADIAN DISCOURSE. THUS, WE RESTORED SOME CONTRIBUTIONS TO THE REFLECTIONS ON THE RELATIONS BETWEEN GEOGRAPHY AND LITERATURE. WE INFERRED THAT MACHADO DE ASSIS tEXTS HAVE A GREAT MOVEMENT OF TRANSFORMATIONS IN THE CARIOCA URBAN AREA, LEAVING BEHIND ITS COLONIAL LANDSCAPE. THE CITY OF COLONIAL FEATURES STARTED TO BECOME EXCITING AND MODERN AND SAW ITS PUBLIC AREAS bEING TAKEN bY THE PEOPLE, NEW RHYTMS AND CHARACTERS. WHEN WE GO THROUGH THE LITERARY teXt WE CAN OBSERVE that tHE SPACE IS PRESENTEd IN SEVERAL WAYS IN THE MACHADIAN WRItING, SOMETIMES AS AREA AND OTHERS AS PLACE, AS THE WRITER USED TO BASE IT ON A STREET, A PARK, A WAY, A BEACH OR A SMALL FARM. THEREFORE HE DESCRIBED IN HIS LITERARY WORK, PIECES OF AN EVOLVING CITY. THE STREETS, PARKS AND HILLS APPEAR AS VALUED AND SENTIMENTAL AREAS, WHERE THE EXPERIENCES THAT HAPPEN CHARACTERIZE THEM AS PLACES, WHILE THE COASTAL AREA CAN BE CHARACTERIZED AS A SPACE WICH WENT THROUGH A GREAT ECONOMIC WORTH, MOSTLY THROUGH THE MEDICAL SPEECH.

KEY WORDS: SPACE, PLACE, CULTURE, LITERATURE, RIO DE JANEIRO. 